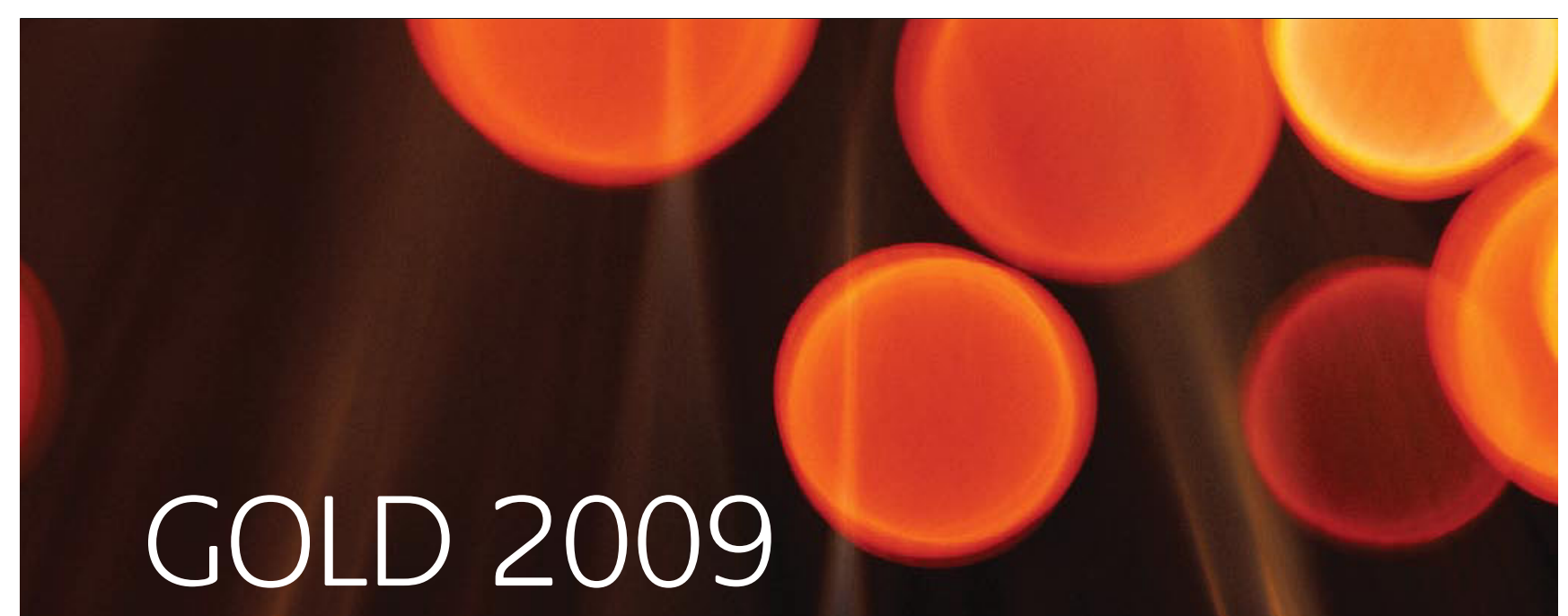

Announcement of the 5th International Conference on gold science, technology and its applications

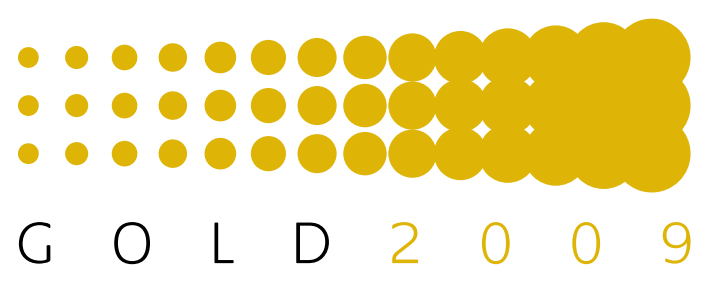

The 5th international conference on gold science, technology and its applications will take place at the University of Heidelberg, in Germany between Sunday 26 - Wednesday 29 July, 2009. This event is being co-organised by the World Gold Council and the University of Heidelberg.

The conference will cover all aspects of the science, technology and applications of gold under the principal themes of: Catalysis, Chemistry, Nanotechnology and Materials.

Sponsored by

\section{- BASF}

The Chemical Company
Many aspects of gold science and technology are in an exciting period of discovery with increasing commercial interest in practical applications. We are seeing the discovery of new reactions catalysed by gold... innovative uses of gold nanoparticles... fresh perspectives in gold chemistry... and novel materials science and gold metallurgy. At GOLD 2009, there will be an internationally respected group of keynote speakers, covering all of these topics; they will be announced shortly.

Scientists and technologists in academia and industry have praised previous conferences in this series. Here they can come together to present and discuss the latest advances with colleagues from their own field and at the same time interact with experts from parallel areas of interest. This is a unique, multidsciplinary event, that offers opportunities not afforded by many other conferences.

With its glorious natural setting, a wonderful castle, historic old town and a beautiful river set in the midst of rolling hills, Heidelberg is regarded as one of the most attractive cities in Germany. It is also a progressive city of international importance in the fields of science, research and business. Not only is Germany's oldest university based in Heidelberg (the venue for the conference), but so are a number of outstanding research institutions and industrial companies. It is a truly wonderful setting for GOLD 2009 and we look forward to welcoming you to see for yourself next year!

Further news and the first Call for Papers will be made shortly, but in the meantime additional details on the conference can be found on the website.

www.gold2009.org 